This document is the accepted manuscript version of the following article: Hemberger, P., Pan, Z., Bodi, A., van Bokhoven, J. A., Ormond, T. K., Ellison, G. B., ... Baraban, J. H. (2020). On the threshold photoelectron spectrum of fulvenone, a reactive ketene derivative in lignin valorization.

WILEY-VCH chemphyschem. https://doi.org/10.1002/cphc. 202000477

\title{
On the Threshold Photoelectron Spectrum of Fulvenone, a Reactive Ketene Derivative in Lignin Valorization
}

\author{
Patrick Hemberger, ${ }^{a *}$ Zeyou Pan, ${ }^{a, b}$ Andras Bodi, ${ }^{a}$ Jeroen A. van Bokhoven, ${ }^{b, c}$ Thomas K. Ormond, ${ }^{d}$
}

G. Barney Ellison, ${ }^{d}$ Nadav Genossar ${ }^{e, f}$ and Joshua H. Baraban ${ }^{\mathrm{e} *}$

[a] Dr. Patrick Hemberger, Zeyou Pan, Dr. Andras Bodi

Laboratory for Synchrotron Radiation and Femtochemistry

Paul Scherrer Institute

$\mathrm{CH}-5232$ Villigen PSI, Switzerland

E-mail: patrick.hemberger@psi.ch

[b] Zeyou Pan, Prof. Dr. Jeroen A. van Bokhoven

Institute for Chemical and Bioengineering, Department of Chemistry and Applied Biosciences

ETH Zurich

Zurich, Switzerland

[c] Prof. Dr. Jeroen A. van Bokhoven

Laboratory for Catalysis and Sustainable Chemistry

Paul Scherrer Institute

$\mathrm{CH}-5232$ Villigen PSI, Switzerland

[d] Thomas K. Ormond and Prof. Dr. G. Barney Ellison

Department of Chemistry and Biochemistry

University of Colorado, Boulder

Colorado 80309-0215, United States

[e] Nadav Genossar and Dr. Joshua H. Baraban

Department of Chemistry

Ben Gurion University of the Negev

Beer Sheva 84105, Israel

E-mail: jbaraban@bgu.ac.il

[f] Nadav Genossar

Israel Atomic Energy Commission

Tel Aviv Israel 61070

Supporting information for this article is given via a link at the end of the document.

\begin{abstract}
Unveiling reaction mechanisms by isomer-selective detection of reactive intermediates requires advanced spectroscopic knowledge. We study the photoionization of fulvenone $\left(\mathrm{c}-\mathrm{C}_{5} \mathrm{H}_{4}=\mathrm{C}=\mathrm{O}\right)$, a reactive ketene species relevant in catalytic pyrolysis of lignin, which was generated by pyrolysis of 2-methoxy acetophenone. The highresolution threshold photoelectron spectrum (TPES) with vacuum ultraviolet synchrotron radiation revealed well-resolved vibrational transitions, assigned to ring deformation modes of the cyclopentadienyl moiety. The adiabatic ionization energy was determined to be $8.25 \pm 0.01 \mathrm{eV}$ and is assigned to the $\widetilde{\mathbf{X}}^{+2} \mathrm{~A}_{2} \leftarrow \widetilde{\mathbf{X}}$ ${ }^{1} A_{1}$ transition. $A$ broad and featureless band arising at $9 \mathrm{eV}$ is associated with the $\widetilde{\mathbf{A}}^{+}{ }^{2} \mathrm{~B}_{1} \leftarrow \widetilde{\mathbf{X}}{ }^{1} \mathrm{~A}_{1}$ excitation. A conical intersection is responsible for the ultrafast relaxation of the fulvenone cation from the $\widetilde{\mathbf{A}}^{+}$into the $\widetilde{\mathbf{X}}^{+}$state resulting in a featureless and lifetime broadened band. These insights will increase the detection capabilities for fulvenone and thereby help to elucidate reaction mechanisms in lignin catalytic pyrolysis.
\end{abstract}

\section{Introduction}

Ketenes are widely used in synthetic organic chemistry. Thanks to their high reactivity towards nucleophiles, they are building blocks for amides, carboxylic acids and anhydrides, and can be utilized in cycloaddition reactions to yield cyclic ketones. Ketenes have recently come into the spotlight of catalysis and raised many questions there: Are they merely precursors for acetate species on the catalyst surface? Do they play an actual role in the catalytic cycle ${ }^{[1]}$ The simplest ketene, ethenone, was identified as a mildly reactive species in syngas conversion to yield $\mathrm{C}_{2}-\mathrm{C}_{4}$ species selectively. ${ }^{[2]}$ Moreover, the 5 -membered ring species fulvene ketene or fulvenone 1 (see Scheme 1) was recently found, by our groups, to be an intermediate in the unimolecular decomposition of catechol (1,2-benzenediol) and salicylaldehyde $4 .{ }^{[3]}$ Furthermore, fulvenone $\mathbf{1}$ plays an important role in lignin valorization and is a central intermediate in the dehydration mechanism to form phenol and benzene in the transmethylation driven guaiacol catalytic fast pyrolysis (CFP). ${ }^{[4]}$ Bierkandt et al. recently observed $\mathbf{1}$ in a laminar premixed anisole flame. ${ }^{[5]}$ However, due to the reactive and elusive nature of 1, standard chemical analysis tools, such as GC/MS and NMR, fail to detect it. This calls for advanced spectroscopic techniques to isomerselectively detect $\mathbf{1}$ in reactive environments; the primary prerequisite for such studies is clean and efficient generation of the target reactive intermediate. In 1971, Grützmacher and Hübner obtained $\mathbf{1}$ in high yields by pyrolysis of 1,2dinitrobenzene or methyl salicylate. Both precursors produced the keto carbene intermediate 2 , which quickly undergoes Wolff<smiles>O=C=C1C=CC=C1</smiles>
Scheme 1 Reaction mechanism to yield fulvenone 1. 
rearrangement. ${ }^{[6]}$ They used electron ionization mass spectrometry (EIMS) to determine the ionization energy (IE) as $8.95 \mathrm{eV}^{[7]}$ Baird et al. photolyzed diazocyclopentadiene (c$\mathrm{C}_{5} \mathrm{H}_{4}=\mathrm{N}_{2}$ ), produced the cyclopentadienylidene $\left(\mathrm{c}-\mathrm{C}_{5} \mathrm{H}_{4}\right.$ :) carbene, which subsequently reacted with $\mathrm{CO}$ in a low temperature matrix to generate 1. The $I R$ spectrum showed a strong $C=C=O$ stretching vibration at $2232 \mathrm{~cm}^{-1}$, while the UV spectrum exhibited a broad band with additional features arising at around $260 \mathrm{~nm} \cdot{ }^{[8]}$ Nagata et al. also measured the infrared spectrum of 1 as produced upon $280 \mathrm{~nm}$ photolysis of 2-iodophenol in an argon matrix. ${ }^{[9]}$ In their kinetic analysis, they found that the intermediately produced keto carbene $\mathbf{2}$ is subject to Wolff rearrangement after $\mathrm{HI}$ elimination producing the ketene 1 . Other synthetic routes to fulvenone 1 were established by Koch and Wentrup, who produced 6-carbonylcyclohexa-2,4-dienone 3 from various precursors, which yielded 1 after decarbonylation. ${ }^{[10]}$ Schulz and Schweig used diazocyclohexadienone to synthesize 1 in situ, performed the first photoelectron spectroscopic study, and assigned the bands at 8.56 and $9.06 \mathrm{eV}$ to the $\widetilde{\mathbf{X}}^{+2} \mathrm{~A}_{2}$ and $\widetilde{\mathrm{A}}^{+}{ }^{2} \mathrm{~B}_{1}$ ion states, respectively. ${ }^{[11]}$ Later, Bock et al. remeasured the conventional photoelectron spectrum, determined the ionization energies as 8.39 and $8.98 \mathrm{eV}$, respectively and revealed some band structure, which they did not discuss in detail. ${ }^{[12]}$ The scatter among the reported ionization energies of fulvenone 1 as determined by EIMS ${ }^{[7]}$ and PES ${ }^{\left[11 \mathrm{~b},{ }^{12]} \text { motivated }\right.}$ us to produce this reactive species in high yield and measure its threshold photoelectron spectrum. Furthermore, although techniques like photoelectron, infrared and ultraviolet spectroscopy can detect reactive intermediates isomerselectively, they lack the multiplexing advantage. This makes it difficult to use these techniques in complex reaction mixtures, e.g., in catalysis or in flames, where a multitude of species is present at the same time. Photoelectron photoion coincidence spectroscopy (PEPICO) with vacuum ultraviolet synchrotron (VUV) radiation resolves this issue as it allows one to measure photoion mass-selected threshold photoelectron spectra and neglect contributors in other mass channels completely. ${ }^{[13]}$ For the detection of constitutional isomers, the experimental spectra are compared to either reference spectra or Franck-Condon simulations; it has been shown that this approach works well for reactive environments such as catalysis ${ }^{[4,14]}$, flames ${ }^{[15]}$, pyrolysis ${ }^{[3}$ ${ }^{16]}$, or fluorine abstraction experiments. ${ }^{[17]}$ Understanding these spectra is a prerequisite for the correct assignment of reactive species and ultimately to elucidate the underlying reaction mechanisms and generate predictive models.

In this contribution, we produce fulvenone 1 from 2methoxyacetophenone 5 (see Scheme 2) in a Chen-type pyrolysis microreactor ${ }^{[18]}$ to obtain high-resolution threshold photoelectron spectra (TPES), determine the active vibrational modes of the cation, and discuss the spectroscopic insights gained with the aid of quantum chemical calculations and FranckCondon simulations. For comparison and to confirm clean production of $\mathbf{1}$, we have also used salicylaldehyde 4 as a fulvenone precursor.

\section{Results and Discussion}

As shown previously, salicylaldehyde (2-hydroxybenzaldehyde) as well as catechol (1,2-dihydroxybenzene) can produce fulvenone upon pyrolysis in different microreactors. ${ }^{[3]}$ However, these precursors cannot be fully converted before the fragile fulvenone ketene further decomposes. In order to maximize the conversion to fulvenone, we have used 2-methoxy acetophenone (5) as a precursor, in which, thanks to the low $\mathrm{O}-\mathrm{CH}_{3}$ bond energy, methyl loss is facilitated.

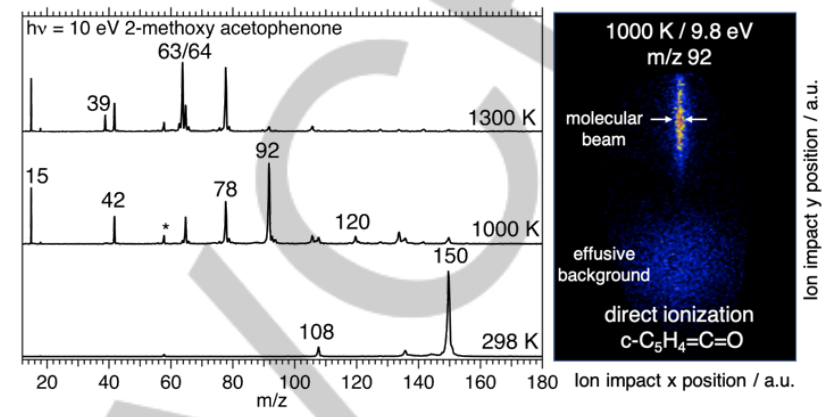

Figure 1 Mass spectra of 2-methoxyacetophenone (2MA, $\mathrm{m} / \mathrm{z} 150)$ at different reactor temperatures as measured at $10 \mathrm{eV}$ photon energy. Upon heating to $1000 \mathrm{~K}, 2 \mathrm{MA}$ is demethylated to yield $\mathrm{m} / \mathrm{z} 120$, which is subject to a decarbonylation reaction to generate the fulvenone ketene, $\mathrm{m} / \mathrm{z} 92$, in high yield. Lighter decomposition products such as $\mathrm{m} / \mathrm{z} 78,63,64,42$ and 39 are produced in parallel or sequential reaction channels. At $1300 \mathrm{~K}$, fulvenone further decomposes to $\mathrm{m} / \mathrm{z} 64$ by another decarbonylation reaction. Thanks to the photoion mass-selection of the PEPICO technique, contributions from other reaction products to the ms-TPES signal of fulvenone can be neglected. To rule out dissociative ionization, velocity map ion images of $\mathrm{m} / \mathrm{z} 92$ were recorded (right panel), which show a molecular beam component with a narrow speed distribution, indicative of direct ionization.

The precursor 5 was vaporized in an in-vacuum sample container, mixed with argon carrier gas and expanded through a $100 \mu \mathrm{m}$ pinhole into the pyrolysis microreactor. A molecular beam is formed, which is skimmed and travels towards the ionization volume of the PEPICO endstation at the Swiss Light Source. Representative mass spectra are depicted in Figure 1, with a peak at $\mathrm{m} / \mathrm{z} 150$ at room temperature, assigned to 5 . Methyl radical loss in dissociative photoionization is responsible for the peak at $\mathrm{m} / \mathrm{z}$ 135 (6), which was confirmed by velocity map ion imaging (VMI, see Figure S1, supporting information). Smaller contributions from anisole or 2-hydroxy acetophenone or 2-anisaldehyde in the sample, probably due to the synthesis of $\mathbf{5}$, were also assigned at $\mathrm{m} / \mathrm{z} 108$ and 136 . Upon increasing the pyrolysis temperature to $1000 \mathrm{~K}$, a new set of peaks rises, amongst them $\mathrm{m} / \mathrm{z} 120,92,78$, $64,63,42$ and 39. Species at $\mathrm{m} / \mathrm{z} 120$ and 92 are due to the formation of the two ketene species 6-carbonylcyclohexa-2,4dienone $(\mathrm{m} / \mathrm{z} 120,3)$ and fulvenone 1 as produced after subsequent demethylation and decarbonylation reactions (see Scheme 2, upper path). It is however conceivable that after the initial methyl cleavage from $\mathbf{5}$, a CO loss produces the acetylcyclopentadienyl radical $(\mathrm{m} / \mathrm{z} 107,7$, see Scheme 2, lower path), which could not be observed, probably due to its low thermal stability. Demethylation may produce the fulvenone 1 in a second reaction pathway. Other products visible in the mass spectrum are likely due to the decomposition of the ketene 1 or due to parallel reaction pathways yielding, e.g., benzene $(\mathrm{m} / \mathrm{z} 78)$. As the focus of this study is the spectroscopy of the fulvenone $\mathbf{1}$, we will forgo a complete analysis of the reaction pathways of 5 herein.

To further optimize ketene formation and to investigate contributions from dissociative ionization at higher photon 
energies, we obtained velocity map images (VMI) of the photoions associated with $\mathrm{m} / \mathrm{z}$ 92, as shown in Figure 1. The upper part of the VMI exhibits a narrow lateral velocity distribution, indicative for the molecular beam of fulvenone, without contributions of dissociative ionization even at photon energies as high as $10 \mathrm{eV}$. Note that the latter would broaden the lateral velocity distribution at the position of the molecular beam (Figure S1, center), owing to kinetic energy release upon dissociative photoionization. Scattering and rethermalization of the molecular beam in the ionization chamber and subsequent ionization is responsible for the broad background at the bottom of the VMI in Figure 1.

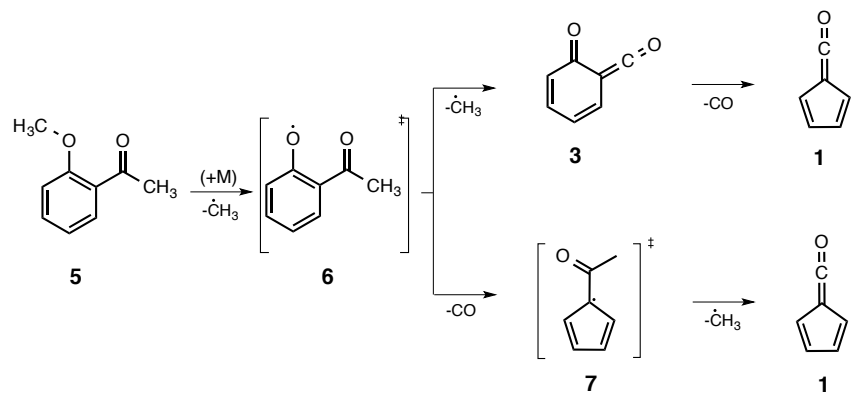

Scheme 2 Formation of fulvenone 1 from 2-methoxyacetophenone 5 . Two reaction pathways are shown that yield the reactive ketene 1 after subsequent demethylation and decarbonylation steps.

\section{Threshold Photoelectron Spectrum of Fulvenone}

Figure 2 shows the photoion mass-selected threshold photoelectron spectrum (ms-TPES) of the fulvenone ketene, as produced from 2-methoxy acetophenone 5 at ca. $1100 \mathrm{~K}$ in our $\mathrm{SiC}$ microreactor. For comparison, the spectrum based on precursor $\mathbf{4}$ is also shown. The two are in good agreement, although the one from $\mathbf{4}$ exhibits a lower signal to noise ratio. The TPE signal starts to rise at around $8 \mathrm{eV}$ and exhibits four distinctly resolved peaks at $8.24,8.32,8.37$ and $8.41 \mathrm{eV}$, and turns into a broad and structureless band from 8.9 to $9.8 \mathrm{eV}$. By taking into account the Stark-shift $(11 \mathrm{meV}),{ }^{[19]}$ we determine the adiabatic ionization energy (AIE) to be $8.25 \pm 0.01 \mathrm{eV}$, correcting previous literature values by $0.15-0.70 \mathrm{eV}$ (Table 1). The broad and featureless onset below the AIE is assigned to hot and sequence band transitions, due to insufficient cooling in the molecular beam expansion. ${ }^{[20]}$ The second band is centered at $9.0 \mathrm{eV}$ in our msTPE spectrum, with a broad and slightly step-like decreasing threshold photoelectron signal. Schultz et al. assigned the two bands in their conventional PES study to $\widetilde{\mathbf{X}}^{+}{ }^{2} \mathrm{~A}_{2} \leftarrow \widetilde{\mathbf{X}}{ }^{1} \mathrm{~A}_{1}$ (8.38 $\mathrm{eV})$ and the $\widetilde{\mathrm{A}}^{+}{ }^{2} \mathrm{~B}_{1} \leftarrow \widetilde{\mathbf{X}}{ }^{1} \mathrm{~A}_{1}(8.98 \mathrm{eV})$ ionization transitions, respectively. ${ }^{[12]}$ Above $9 \mathrm{eV}$ the ms-TPES and PES ${ }^{[12]}$ show the same declining signal, which indicates decreasing FranckCondon factors, rather than fragmentation of the fulvenone cation. This was further confirmed by velocity map ion images (Figure $\mathrm{S} 1$ ) of the mass channels below $\mathrm{m} / \mathrm{z} 92$, which do not show velocity components perpendicular to the molecular beam axis, i.e., none of these ions is a dissociation product of heavier parent ions. Our experimentally determined value for the AIE $\left(\widetilde{\mathbf{X}}^{+2} \mathrm{~A}_{2} \leftarrow\right.$ $\left.\widetilde{\mathbf{X}}{ }^{1} A_{1}\right)$ is in excellent agreement with computations using composite methods, as summarized in Table 1. In addition to the ms-TPES, we plot the photoionization (PI) spectrum for comparison (Figure 2, blue curve), which exhibits a step-like onset at the ionization energy and monotonically increases subsequently, due to the smoothly increasing ionization cross section. Below $8.2 \mathrm{eV}$, we find some activity of hot- and sequence band transitions, in agreement with the TPES data. In order to obtain more insights into the spectroscopy and electronic structure we have performed computations at different levels of theory. Tables S1-S3 (SI) summarize the most important geometry changes upon ionization of fulvenone while Figure 3 provides information on the frontier orbitals of the $C_{2 v}$ symmetric neutral species $\left(\widetilde{\mathbf{X}}^{1} A_{1}\right)$. In a Koopmans' theorem picture, the electron is removed from the highest occupied molecular orbital (HOMO), which is of a symmetry and thus leads to the $\widetilde{\mathbf{X}}^{+{ }^{2} \mathrm{~A}_{2}}$ cation state. The HOMO $(\pi)$ possesses bonding character along the $\mathrm{C}=\mathrm{C}$ double bonds. Consequently, removing electron density during the ionization process will decrease the binding character of the contributing MOs, which leads to an increased bond length of $\mathrm{C} 2=\mathrm{C} 4$ (atom numbering Figure 3) and C3=C5 (Table S1-3, SI) at the cyclopentadiene moiety, respectively. At the same time, the bond length of C4-C5 decreases due to decreasing anti-bonding character along this coordinate, while the bond angles in the fivemembered ring are only slightly affected.

$\mathrm{m} / z 92 \mathrm{~ms}$-TPES fulvenone from

$\mathrm{m} / \mathrm{z} 92 \mathrm{~ms}$-TPES fulvenone from 4

$\mathrm{m} / \mathrm{z} 92 \mathrm{PI}$ spectrum fulvenone from

$\underset{\tilde{X}^{1}}{\mathrm{AlE}}=8.25 \mathrm{eV} \quad \mathrm{AlE}=9.0 \mathrm{eV}$

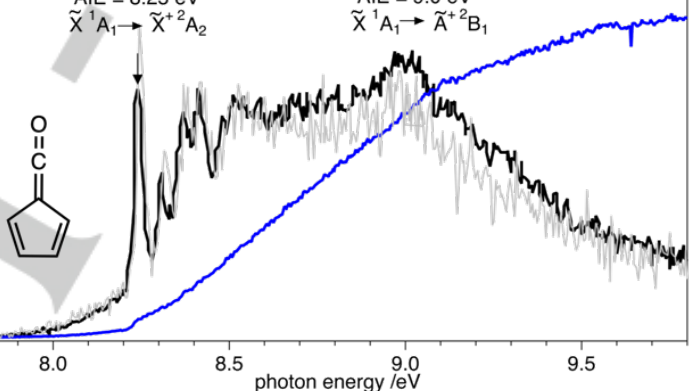

Figure 2 Threshold photoelectron spectrum (TPES) and photoionization (PI) spectrum of the fulvenone ketene at $\mathrm{m} / \mathrm{z} 92$ obtained from precursors $\mathbf{5}$ and $\mathbf{4}$. The PI spectrum shows a monotonically increasing signal above the ionization energy. The ms-TPES provides vibrationally resolved information on the cationic ground state of fulvenone. The Stark-shift corrected adiabatic ionization energy (AIE) is assigned to the first peak at $8.25 \pm 0.01 \mathrm{eV}$, while a broad and featureless band, centered at $9.0 \mathrm{eV}$, is associated with transitions into the excited ion state $\left(\widetilde{A}^{+2} \mathrm{~B}_{1}\right)$.

Table 1 Summary of the experimentally and theoretically obtained ionization energies of the fulvenone ketene. All values are in $\mathrm{eV}$.

\begin{tabular}{|c|c|c|c|}
\hline method & $\operatorname{AIE}\left(\widetilde{\mathrm{X}}^{+}{ }^{2} \mathrm{~A}_{2}\right)$ & $\operatorname{AIE}\left(\widetilde{\mathrm{A}}^{+2} \mathrm{~B}_{1}\right)$ & source \\
\hline $\begin{array}{l}\text { experimental: } \\
\text { ms-TPES } \\
\text { PES } \\
\text { EI-MS }\end{array}$ & $\begin{array}{c}8.25 \pm 0.01 \\
8.56 / 8.39 \\
8.95\end{array}$ & $\begin{array}{c}9.0 \\
9.06 / 8.98\end{array}$ & $\begin{array}{l}\text { this work } \\
\text { ref. }{ }^{[11 a, 12} \\
\text { ref. }^{[7]}\end{array}$ \\
\hline $\begin{array}{l}\text { theory: } \\
\text { CBS-QB3 } \\
\text { CBS-APNO } \\
\text { G3 } \\
\text { G4 } \\
\text { W1BD } \\
\text { MP2/ 6-311++G(d,p) } \\
\text { CCSD/aug-cc-pVDZ } \\
\text { EOMIP-CCSD/ANO0 }\end{array}$ & $\begin{array}{l}8.29 \\
8.25 \\
8.26 \\
8.24 \\
8.27 \\
8.23 \\
7.94 \\
8.09\end{array}$ & $\begin{array}{c}- \\
8.79 \\
8.97 \\
- \\
- \\
9.15 \\
8.42 \\
8.50\end{array}$ & $\begin{array}{l}\text { this work } \\
\text { this work } \\
\text { this work } \\
\text { this work } \\
\text { this work } \\
\text { this work } \\
\text { this work } \\
\text { this work }\end{array}$ \\
\hline $\begin{array}{l}\text { EOMIP-CCSD/cc-pVTZ } \\
\text { EOMIP-CCSD/cc-pVQZ }\end{array}$ & $\begin{array}{c}\operatorname{VIE}\left(\widetilde{\mathrm{X}}^{+2} \mathrm{~A}_{2}\right) \\
8.55 \\
8.66\end{array}$ & $\begin{array}{c}\operatorname{VIE}\left(\widetilde{A}^{+2} \mathrm{~B}_{1}\right) \\
8.93 \\
9.04\end{array}$ & $\begin{array}{l}\text { this work } \\
\text { this work }\end{array}$ \\
\hline
\end{tabular}



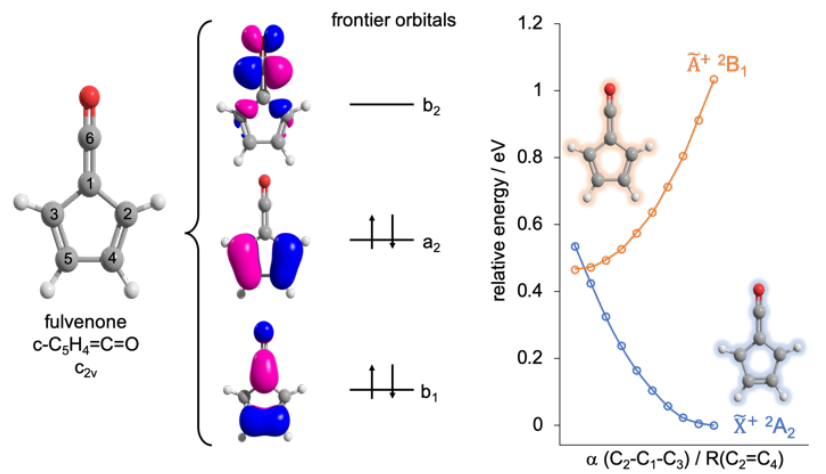

Figure 3 Energy diagram of the three frontier orbitals of the fulvenone, calculated at HF/6-311G(d,p) level of theory. The highest occupied molecular orbital (HOMO) is of $\mathrm{a}_{2}$ symmetry and has bonding character along $\mathrm{C} 2 / 3=\mathrm{C} 4 / 5$ double bond in the cyclopentadiene ring. HOMO-1 $\left(b_{1}\right)$ has a binding component along the $\mathrm{C} 4-\mathrm{C} 5$ bond of the ring and the $\mathrm{C} 1=\mathrm{C} 6$ and antibonding character at the carbonyl function $\mathrm{C} 6=\mathrm{O}$. The right panel shows the conical intersection between the $\widetilde{\boldsymbol{X}}^{+2} \mathrm{~A}_{2}$ and the $\widetilde{A}^{+2} \mathrm{~B}_{1}$ state, close to the equilibrium geometry of the $\widetilde{A}^{+}$state, which is the reason for the short lifetime of the first electronically excited state and the unstructured band centered at $9 \mathrm{eV}$. Single point EOMIP-CCSD/cc-pVDZ computations, along the reaction coordinate between the $\widetilde{\boldsymbol{X}}^{+}$and $\widetilde{\boldsymbol{A}}^{+}$state, were performed to obtain the excitation energies.

Photoion mass-selected threshold photoelectron spectra are an indispensable tool to determine species compositions and identify reactive intermediates in extreme environments, such as combustion, ${ }^{[15]}$ pyrolysis and catalysis ${ }^{[4,14 b, 21]}$. Reference spectra or Franck-Condon simulations are utilized to reproduce the vibrational features to enable isomer-selective detection. Thus, it is of fundamental importance to accurately predict and understand the vibrational features in the TPE spectra. ${ }^{[22]} \mathrm{FC}$ simulations have been carried out in the double harmonic approximation including Duschinsky rotation, at the optimized geometries using force constant matrices of the $\widetilde{\mathbf{X}}^{1} \mathrm{~A}_{1}$ neutral and the $\widetilde{\mathbf{X}}^{+2} \mathrm{~A}_{2}$ cation states. The FC predicted spectrum (red) along with the experimental one (black) is depicted in Figure 4, showing excellent agreement in the low energy part.

Besides the fundamental transition, located at $8.25 \mathrm{eV}$ (Stark-shift corrected), three totally symmetric modes are active upon ionization. The lowest energy one is found $70 \mathrm{meV}\left(565 \mathrm{~cm}^{-1}\right)$ above the origin and assigned to the $v_{10}$ ring deformation mode at $559 \mathrm{~cm}^{-1}$. At around $8.4 \mathrm{eV}$, we can identify the third transition with an experimental value of $1045 \mathrm{~cm}^{-1}$, which compares well with the $\mathrm{C}=\mathrm{C}$ stretching vibration computed at $1073 \mathrm{~cm}^{-1}$ ( 18 ). Note that the largest geometry change is predicted along this mode upon ionization. Another ring deformation mode is found at $0.18 \mathrm{eV}$ above the origin with an experimental vibrational frequency $1434 \mathrm{~cm}^{-1}$ and a theoretical value of $v_{5}=1441 \mathrm{~cm}^{-1}$. At higher photon energies, the features are only barely resolved in the experimental ms-TPES, and the transitions are mostly determined by combination bands between the discussed modes. FC simulations at different levels of theory are presented in the supporting information (Figure S2). All of them agree with the experimental data of the ground state, and the nuances are due to the slightly different geometries (see Tables S1-S3 for comparison). It is worth comparing the $\widetilde{\mathbf{X}}^{+}{ }^{2} \mathrm{~A}_{2}$ part of ms-TPES of fulvenone to that of cyclopentadienone. ${ }^{[23]}$ It is not surprising that similar vibrational features are observed in both compounds, as the ionization takes place from basically the same $\mathrm{a}_{2} \mathrm{HOMO}$, which is purely located at the cyclopentadiene moiety.
Consequently, a similar change in geometry and activity of modes are expected.

While the low-energy part of the experimental spectrum is well reproduced by the ground state simulation it significantly deviates from the model above $8.6 \mathrm{eV}$, which is due to transitions into the excited cation state $\widetilde{\mathrm{A}}^{+}{ }^{2} \mathrm{~B}_{1} \leftarrow \widetilde{\mathbf{X}}^{1} \mathrm{~A}_{1}$, as assigned by Bock et al. ${ }^{[12]}$ Indeed EOMIP-CCSD calculations find vertical ionization energies (VIE), for the $\widetilde{\mathrm{A}}^{+2}{ }^{2} \mathrm{~B}_{1}$ state close to $9 \mathrm{eV}$ (see Table 1), in excellent agreement with the maximum of the second band. The geometries of the $\widetilde{\mathrm{A}}^{+2} \mathrm{~B}_{1}$ state are summarized in Table $S 3$ and show some difference especially at the $\mathrm{C} 4=\mathrm{C} 5$ bond length if TDDFT and EOM-IP-CCSD results are compared. To populate the $\widetilde{\mathrm{A}}^{+}$state, the electron is removed from HOMO-1 ( $\mathrm{b}_{1}$ symmetry, see Figure 3 ), which results in increased $\mathrm{C} 4-\mathrm{C} 5$ and $\mathrm{C} 5-\mathrm{C} 6$ bond lengths, together with a flatter $\mathrm{C} 2-\mathrm{C} 1-\mathrm{C} 3$ angle. It is worth noting that the HOMO-1 of fulvenone can be seen as a linear combination of the HOMO of ketene, with the $b_{1}\left(e_{1}{ }^{\prime \prime}\right)$ orbital of cyclopentadienyl.

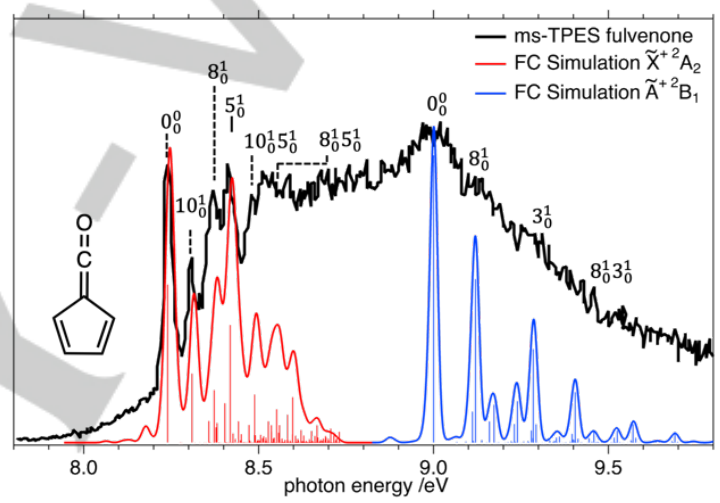

Figure 4 ms-TPES of fulvenone together with Franck-Condon simulations for the $\widetilde{\boldsymbol{X}}^{+}{ }^{2} \mathrm{~A}_{2} \leftarrow \widetilde{\boldsymbol{X}}^{1} \mathrm{~A}_{1}$ (red) and $\widetilde{\boldsymbol{A}}^{+}{ }^{2} \mathrm{~B}_{1} \leftarrow \widetilde{\boldsymbol{X}}{ }^{1} \mathrm{~A}_{1}$ (blue) transitions, respectively. The simulations are based on harmonic frequencies and geometries calculated at the $\operatorname{CCSD}(\mathrm{T}) / \mathrm{ANOO}$ and EOM-IP-CCSD/ANOO for the neutral and ionized states, respectively.

The FC simulation of the $\widetilde{\mathrm{A}}^{+}{ }^{2} \mathrm{~B}_{1} \leftarrow \widetilde{\mathbf{X}}^{1} \mathrm{~A}_{1}$ transition, at EOM-IPCCSD level of theory, is also presented in Figure 4. The differences between the model and the experimental spectrum show the limits of the FC approach for short-lived electronic states coupling strongly to neighboring ones. First, there is a clear Franck-Condon gap between 8.6 and $9 \mathrm{eV}$ in the computed spectrum, which is clearly absent in the experimental one. Since the conventional photoelectron spectrum of Bock et al. ${ }^{[12]}$ shows the same band shape, autoionization, i.e., ionization following the resonant excitation to neutral valence of Rydberg states above the IE, can be ruled out. Furthermore, additional cation states are not identified between 8.6 and $9 \mathrm{eV}$ either by TDDFT or by EOMIP-CCSD computations. This leaves only a non-adiabatic behavior of the $\widetilde{\mathbf{X}}^{+}$and $\widetilde{\mathbf{A}}^{+}$states as the explanation. Second, the Franck-Condon simulation for the $\widetilde{\mathrm{A}}^{+}$state shows pronounced vibrational transitions, of the $\mathrm{C} 2-\mathrm{C} 1-\mathrm{C} 3$ bending $\left(18=968 \mathrm{~cm}^{-1}\right)$ and the $\mathrm{C}=\mathrm{O}$ stretching $\left(\nu_{3}=2300 \mathrm{~cm}^{-1}\right)$ modes, which structure is washed out in the experimental ms-TPES. This is probably due to efficient vibrational coupling between the ground and excitedstate cation states due to their energetic proximity, which is also reflected by an imaginary frequency found along a complex asymmetric in-plane ring deformation mode in the EOM-IPCCSD/ANOO calculations of the $\widetilde{\mathbf{A}}^{+}$state. This imaginary frequency breaks the $C_{2 v}$ symmetry and was excluded in the FC simulation of Figure 4 (blue trace). The large difference of the experimental and calculated excited state spectrum is probably 
caused by vibronic coupling, which is not taken into account in the FC model. Furthermore, the broad and featureless band shape in our ms-TPES may be caused by a conical intersection, which will result in an ultrafast relaxation of the population of the excited $\widetilde{\mathbf{A}}^{+}$ ${ }^{2} \mathrm{~B}_{1}$ state into the ion ground state $\left(\widetilde{\mathbf{X}}^{+2} \mathrm{~A}_{2}\right)$. Indeed, a conical intersection of the $\widetilde{\mathbf{X}}^{+}$and $\widetilde{\mathbf{A}}^{+}$states can be identified by scanning the coordinate from both equilibrium geometries and calculating the EOM-IP-CCSD/cc-pVDZ potential energy curves, as depicted in Figure 3 (right). A more detailed treatment of this conical intersection requires construction of a vibronic coupling model; however this goes beyond the scope of this work and has not been pursued here. ${ }^{[24]}$ In fact this result shows the limit of the widely applied FC modeling approach to fit experimental ms-TPE spectra for the isomer-selective assignment of reactive intermediates in complex environments. However, we have found that, as was also observed in formamide and acetamide, ${ }^{[25]}$ the lowest energy state at the optimized geometry of the $\widetilde{\mathbf{A}}^{+}$state is indeed the $\widetilde{\mathbf{A}}^{+}$state. This applied to wave function theory methods, which allowed us to carry out, among others, groundstate CBS-APNO and G3 composite method calculations to obtain the adiabatic ionization energies to the excited $\widetilde{\mathbf{A}}^{+}$state, as well (Table 1). These agree well with EOM-IP-CCSD calculations and the general appearance of the TPES.

\section{Conclusion}

We have generated fulvenone 1 , a reactive ketene species, in a pyrolytic microreactor from 2-methoxyacetophenone $\mathbf{5}$ and measured its ms-TPE spectrum using double imaging PEPICO spectroscopy as implemented at the VUV beamline of the Swiss Light Source. We determined the origin of the $\widetilde{\mathbf{X}}^{+}{ }^{2} \mathrm{~A}_{2} \leftarrow \widetilde{\mathbf{X}}^{1} \mathrm{~A}_{1}$ transition in fulvenone to be $8.25 \mathrm{eV}$, in excellent agreement with composite method calculations, and revised the literature values by 150 to $700 \mathrm{meV}$. Franck-Condon simulations have been performed to model the vibrational features, which were assigned to ring deformation and $\mathrm{C}=\mathrm{C}$ stretching vibrations. Experimental values for the vibrational modes of elusive and reactive intermediates are non-trivial to obtain but crucial to evaluate theoretical methods. Here, we were able to experimentally determine three vibrational frequencies of the fulvenone cation accurately. A broad and featureless band only $0.5 \mathrm{eV}$ above the ground state and centered at $9.0 \mathrm{eV}$ is assigned to the $\widetilde{\mathrm{A}}^{+}{ }^{2} \mathrm{~B}_{1}$ state. Due to the energetic overlap, confirmed by EOM-IP-CCSD calculations, vibrational coupling between the $\widetilde{\mathbf{X}}^{+}$and $\widetilde{\mathbf{A}}^{+}$states is strong via a conical intersection close to the equilibrium geometry of the $\widetilde{\mathbf{A}}^{+}$state. This results in the ultrafast relaxation of the excited ion state and explains the observed featureless spectrum extending above $9 \mathrm{eV}$. Understanding the electronic spectra is crucial for the isomer-selective assignment of elusive intermediates in reactive mixtures, which is essential for their insitu detection and quantification. Our data may help to develop reaction mechanisms for lignin catalytic fast pyrolysis and to design predictive chemical models for the conversion of this renewable feedstock into fuels and fine chemicals.

\section{Experimental Section \& Theory}

Experiments were performed at the VUV beamline at the Swiss Light Source located at the Paul Scherrer Institute (Switzerland). ${ }^{[26]}$ 2-methoxy acetophenone (2MA) was used as the precursor for the fulvenone ketene, obtained from Sigma-Aldrich (99\% purity) and used without further purification. It was placed in an oven source and heated to $338 \mathrm{~K}$ to increase the vapor pressure and mixed with argon as buffer gas at a flow rate of $20 \mathrm{sccm}$ at $420 \mathrm{mbar}$. The gas mixture was expanded through a $100 \mu \mathrm{m}$ pinhole into a resistively heated $\mathrm{SiC}$ microtubular reactor $(L=40$ $\mathrm{mm}, \mathrm{iD}=1 \mathrm{~mm}, \mathrm{oD}=2 \mathrm{~mm}$ ). The design of the reactor is a variant of the widely applied Chen-type reactor, which is a robust device for the selective generation of reactive intermediates from stable precursors. ${ }^{[18]}$ We estimate the residence time and pressure in the reactor to be a ca. $100 \mu \mathrm{s}$ and few tens of mbar, respectively. ${ }^{[27]}$ After reaction, the gas sample leaves the reactor, expands into high-vacuum to form a molecular beam, which is skimmed with a $2 \mathrm{~mm}$ skimmer and travels towards the ionization region of the CRF-PEPICO ${ }^{[28]}$ spectrometer. The VUV light is produced by a bending magnet, collimated onto a $150 \mathrm{l} / \mathrm{mm}$ grating and focused onto the exit slits, allowing for a 1500 resolving power $(6 \mathrm{meV} @ 8 \mathrm{eV})$ at these conditions. A rare gas filter, filled with a mixture of $\mathrm{Ar}, \mathrm{Ne}$, and $\mathrm{Kr}$ at a pressure of $10 \mathrm{mbar}$ over an optical length of $10 \mathrm{~cm}$ suppresses the higher order radiation from the grating. ${ }^{[26]}$ The molecular beam and the VUV synchrotron light are intersected at a $90^{\circ}$ angle in the ionization region. Photoions and photoelectrons are extracted in a constant, $213 \mathrm{~V} \mathrm{~cm}^{-1}$ field, velocity map imaged (VMI) and detected using position sensitive delay-line anode detectors (Roentdek, DLD40) in a multi-start multi-stop scheme. ${ }^{[29]}$ Photoelectron photoion coincidence (PEPICO) techniques allow for measuring photoion mass-selected threshold photoelectron spectra (msTPES). Threshold electrons are selected with $5 \mathrm{meV}$ resolution and corrected for contributions of kinetic energy electrons without off-axis momentum components as outlined by Sztáray and Baer. ${ }^{[30]}$ Due to the DC extraction field in the ionization region, the adiabatic ionization energy (AIE) has to be corrected for the Stark shift of $11 \mathrm{meV}$ using the expression by Chupka et al. ${ }^{[19]} \Delta \boldsymbol{E}=\mathbf{6} .1 \sqrt{\boldsymbol{F}}$, where $\Delta \boldsymbol{E}$ is the shift in $\left[\mathrm{cm}^{-1}\right]$ and $F$ is the electric field in $\left[\mathrm{V} \mathrm{cm}^{-1}\right]$. The validity of this expression was confirmed in a study on iodomethane. ${ }^{[31]}$ Both the photoionization spectrum as well as the ms-TPES were normalized by the photon flux. Gaussian $16^{[32]}$, Q$\mathrm{Chem}^{[33]}$ as well as CFOUR ${ }^{[34]}$ have been used to optimize the geometries and vibrational frequencies of the neutral and ion states at the CCSD/augcc-pVDZ, B3LYP/cc-pVTZ+d, HF/6-311G(d,p) and MP2/6-311++g(d,p), $\operatorname{CCSD}(\mathrm{T}) / \mathrm{ANO} 0$ and EOM-IP-CCSD/ANOO levels of theory, all within the frozen core approximation. ${ }^{[35]}$ Accurate adiabatic ionization energies (AIEs) were also computed utilizing the CBS-QB3, CBS-APNO, G3, G4, and W1BD composite methods. The symmetry of the states refers to the $y z$ principal plane in $C_{2 v}$ and the vibrational modes were numbered according to the Mulliken convention, by dividing into symmetry blocks and decreasing frequency. Threshold photoelectron spectra were simulated utilizing eZspectrum ${ }^{[36]}$ or $[\mathrm{FC}]^{2} .^{[37]}$ The calculated stick spectra were subsequently convoluted with a 20-25 meV Gaussian function to account for the rotational envelope. The potential energy surfaces of both ion states for visualizing the conical intersection were computed by obtaining intermediate structures between the two equilibrium geometries $\left(\widetilde{\mathbf{X}}^{+}{ }^{2} \mathrm{~A}_{2}\right.$ and $\left.\widetilde{\mathbf{A}}^{+}{ }^{2} \mathrm{~B}_{1}\right)$ and performing EOM-IP CCSD/cc-pVDZ single point calculations.

\section{Acknowledgements}

The measurements were performed at the VUV beamline at the Swiss Light Source located at Paul Scherrer Institute, Villigen, Switzerland. P.H. and Z.P. are grateful for the funding by Swiss 
National Science Foundation (SNSF, 200021_178952). A. B., P. H. and Z.P. thank Patrick Ascher for technical assistance. All authors thank Jana Hemberger for designing the TOC picture.

Keywords: ketene $\cdot$ photoelectron photoion coincidence spectroscopy $\cdot$ reactive intermediate $\cdot$ lignin $\bullet$ catalysis

[1] A. D. Chowdhury, J. Gascon, Angew. Chem. Int. Ed. 2018, 57, 14982-14985.

[2] F. Jiao, J. Li, X. Pan, J. Xiao, H. Li, H. Ma, M. Wei, Y. Pan, Z. Zhou, M. Li, et al., Science 2016, 351, 1065-1068.

[3] T. K. Ormond, J. H. Baraban, J. P. Porterfield, A. M. Scheer, P. Hemberger, T. P. Troy, M. Ahmed, M. R. Nimlos, D. J. Robichaud, J. W. Daily, et al., J. Phys. Chem. A 2018, 122, 5911-5924.

[4] P. Hemberger, V. B. F. Custodis, A. Bodi, T. Gerber, J. A. van Bokhoven, Nat. Commun. 2017, 8, 15946.

[5] T. Bierkandt, P. Hemberger, P. Oßwald, D. Krüger, M. Köhler, T. Kasper, Proc. Combust. Inst. 2019, 37, 1579-1587.

[6] W. Kirmse, Eur. J. Org. Chem. 2002, 2002, 2193-2256.

[7] H.-F. Grützmacher, J. Hübner, Liebigs Ann. Chem. 1971, 748, 154-162.

[8] M. S. Baird, I. R. Dunkin, N. Hacker, M. Poliakoff, J. J. Turner, J. Am. Chem. Soc. 1981, 103, 5190-5195.

[9] M. Nagata, Y. Futami, N. Akai, S. Kudoh, M. Nakata, Chem. Phys. Lett. 2004, 392, 259-264.

[10] R. Koch, R. J. Blanch, C. Wentrup, J. Org. Chem. 2014, 79, 6978-6986.

[11] a) R. Schulz, A. Schweig, Tetrahedron Lett. 1979, 20, 59-62; b) A. Schweig, W. Zittlau, Chem. Phys. 1986, 103, 375-382.

[12] H. Bock, T. Hirabayashi, S. Mohmand, Chem. Ber. 1981, 114, 2595-2608.

[13] A. Bodi, P. Hemberger, D. L. Osborn, B. Sztáray, J. Phys. Chem. Lett. 2013, 4, 2948-2952.

[14] a) V. Paunović, P. Hemberger, A. Bodi, N. López, J. PérezRamírez, Nat. Catal. 2018, 1, 363-370; b) P. Hemberger, J. A. van Bokhoven, J. Pérez-Ramírez, A. Bodi, Catal. Sci. Technol. 2020, 10, 1975-1990.

[15] a) J. Krüger, G. A. Garcia, D. Felsmann, K. Moshammer, A. Lackner, A. Brockhinke, L. Nahon, K. Kohse-Höinghaus, PCCP 2014, 16, 22791-22804; b) P. Oßwald, P. Hemberger, T. Bierkandt, E. Akyildiz, M. Köhler, A. Bodi, T. Gerber, T. Kasper, Rev. Sci. Instrum. 2014, 85, 025101.

[16] a) P. Hemberger, A. J. Trevitt, T. Gerber, E. Ross, G. da Silva, J. Phys. Chem. A 2014, 118, 3593-3604; b) P. Hemberger, A. J. Trevitt, E. Ross, G. da Silva, J. Phys. Chem. Lett. 2013, 4, 25462550; c) M. Gerlach, A. Bodi, P. Hemberger, PCCP 2019, 21 , 19480-19487.

[17] H. R. Hrodmarsson, G. A. Garcia, L. Nahon, B. Gans, J.-C. Loison, J. Phys. Chem. A 2019, 123, 9193-9198.

[18] D. W. Kohn, H. Clauberg, P. Chen, Rev. Sci. Instrum. 1992, 63, 4003-4005.

[19] W. A. Chupka, J. Chem. Phys. 1993, 98, 4520-4530.

[20] B. K. Cunha de Miranda, C. Alcaraz, M. Elhanine, B. Noller, P. Hemberger, I. Fischer, G. A. Garcia, H. Soldi-Lose, B. Gans, L. A. Mendes, et al., J. Phys. Chem. A 2010, 114, 4818-4830.

[21] P. Hemberger, A. Bodi, CHIMIA International Journal for Chemistry 2018, 72, 227-232.

[22] a) T. Baer, R. P. Tuckett, PCCP 2017, 19, 9698-9723; b) J. M. Dyke, PCCP 2019, 21, 9106-9136.

[23] T. K. Ormond, P. Hemberger, T. P. Troy, M. Ahmed, J. F. Stanton, G. B. Ellison, Mol. Phys. 2015, 113, 2350-2358.

[24] W. Domcke, H. Köppel, L. S. Cederbaum, Mol. Phys. 1981, 43, 851-875.

[25] A. Bodi, P. Hemberger, J. Phys. Chem. A 2019, 123, 272-283.

[26] M. Johnson, A. Bodi, L. Schulz, T. Gerber, Nucl. Instrum. Methods Phys. Res., Sect. A 2009, 610, 597-603.

[27] Q. Guan, K. N. Urness, T. K. Ormond, D. E. David, G. Barney Ellison, J. W. Daily, Int. Rev. Phys. Chem. 2014, 33, 447-487. [28] B. Sztáray, K. Voronova, K. G. Torma, K. J. Covert, A. Bodi, P. Hemberger, T. Gerber, D. L. Osborn, J. Chem. Phys. 2017, 147, 013944.

[29] A. Bodi, B. Sztáray, T. Baer, M. Johnson, T. Gerber, Rev. Sci. Instrum. 2007, 78, 084102.
[30] B. Sztáray, T. Baer, Rev. Sci. Instrum. 2003, 74, 3763-3768.

[31] A. Bodi, N. S. Shuman, T. Baer, PCCP 2009, 11, 11013-11021. [32] M. J. Frisch, G. W. Trucks, H. B. Schlegel, G. E. Scuseria, M. A Robb, J. R. Cheeseman, G. Scalmani, V. Barone, B. Mennucci, G. A. Petersson, et al., Wallingford CT 2016,

[33] Y. Shao, Z. Gan, E. Epifanovsky, A. T. B. Gilbert, M. Wormit, J. Kussmann, A. W. Lange, A. Behn, J. Deng, X. Feng, et al., Mol. Phys. 2015, 113, 184-215.

[34] CFOUR, a quantum chemical program package written by, J. G. J.F. Stanton, L. Cheng, M.E. Harding, D.A. Matthews, P.G. Szalay, R. J. B. with contributions from A.A. Auer, U. Benedikt, C. Berger, D.E. Bernholdt, Y.J. Bomble, O. Christiansen, F. Engel, R. Faber, M. Heckert, O. Heun, M. Hilgenberg, C. Huber, T.-C. Jagau, D. Jonsson, J. Jusélius, T. Kirsch, K. Klein, W.J. Lauderdale, F. Lipparini, T. Metzroth, L.A. Mück, D.P. O'Neill, D.R. Price, E. Prochnow, C. Puzzarini, K. Ruud, F. Schiffmann, W. Schwalbach, C. Simmons, S. Stopkowicz, A. Tajti, J. Vázquez, F. Wang, J.D. Watts and the integral packages MOLECULE (J. Almlöf and P.R. Taylor), PROPS (P.R. Taylor), ABACUS (T. Helgaker, H.J. Aa. Jensen, P. Jørgensen, and J. Olsen), and ECP routines by A. V. Mitin and C. van Wüllen., For the current version, see http://www.cfour.de.,

[35] J. Almlöf, P. R. Taylor, J. Chem. Phys. 1987, 86, 4070-4077. [36] ezSpectrum, http://iopenshell.usc.edu/downloads., V. A. Mozhayskiy, A. I. Krylov,

[37] S. M. Rabidoux, V. Eijkhout, J. F. Stanton, J. Chem. Theory Comput. 2016, 12, 728-739. 


\section{WILEY-VCH}

\section{ARTICLE}

\section{Entry for the Table of Contents}

Insert graphic for Table of Contents here. ((Please ensure your graphic is in one of following formats))

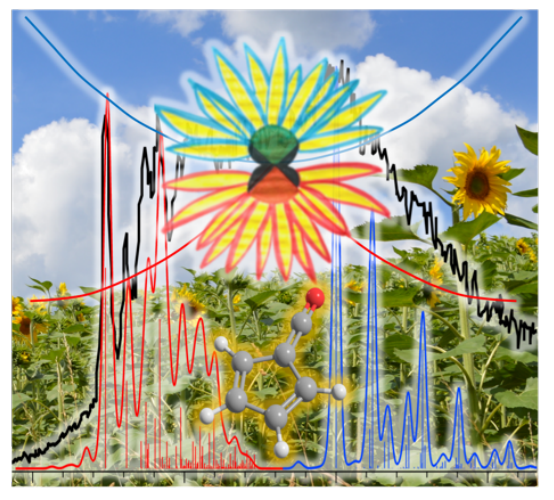

TOC Text: Fulvenone, a reactive ketene in lignin catalytic pyrolysis, was synthesized and characterized in-situ using threshold photoelectron spectroscopy with synchrotron radiation. Two cationic states, strongly coupled via a conical intersection, contribute to the spectrum.

Institute and/or researcher Twitter usernames: @psi_en, @PatHemberger, @andras_bodi 